\title{
Optimization of Multiple Hydraulically Fractured Factors to Maximize the Stimulated Reservoir Volume in Silty Laminated Shale formation, Southeastern Ordos Basin, China
}

\author{
Yu Wang*, Xiao Li, Bo Zhang \\ Key Laboratory of Shale Gas and Geoengineering, Institute of Geology and Geophysics, Chinese Academy of Sciences, \\ Beijing 100029, People's Republic of China. \\ Yu Wang: Email: wangyu@mail.iggcas.ac.cn ( good541571889@126.com )
}

\begin{abstract}
An important inspect that maximizes the stimulated reservoir volume during the hydraulic fracturing design is the multi-factor analysis and optimization. Characterizations of geological setting, geomechanical rock properties and operational factors can provide insight into the fracturing response of formations, which can, in turn be used to optimize the field fracturing treatment. In this work, the response surface methodology was employed to maximize the stimulated area in combination with numerically modeling based on a coupled flow-stress-damage approach, for the typical continental silty laminae shale in China. Seven uncertain parameters with a reasonable range based on silty Laminae Shale, Southeastern Ordos Basin, are used to fit a response of stimulated reservoir area (SRA) as the objective function, and finally identity the optimum design under the parameters base on SRA maximization The motivation of the study is to improve the artificial ability to control the fracturing network propagation by the multi-factor optimization. This work will guide the exploration and development of shale gas and is helpful in optimizing the fracturing design for continental shale, Southeastern Ordos Basin, China.
\end{abstract}

Keywords: Hydraulic fracturing; Silty laminae shale; Mutri-parameter optimization; Response surface methodology; Stimulated reservoir area (SRA)

\section{Introduction}

The success of the "shale gas revolution" in North America has triggered a worldwide fever for shale gas exploration and development (King, 2010; Curtis, 2002; Montgomery et al., 2015; Jarvie et al., 2007). Recently, more and more attention has been paid to the continental shale hydrocarbons in China. The typical continental shale plays in China mainly distribute at the southeast Ordos Basin. The Ordos Basin covers $26 \times 104 \mathrm{~km}^{2}$ and is a huge, hydrocarbon prolific basin located in the middle of northern China, possessing giant gas fields in the Upper Palaeozoic and oil fields in the Ordovician, Triassicand Jurassic strata (Liu et al., 2012; Tang et al., 2012; Luo and Ji, 2013). The main stratigraphy of the basin is the Yanchang formation, which consists of the upper Triassic strata, can be subdivided into ten members, and are named Member Chang1 through Chang10 (Tang et al., 2014). All members consist of shales, mudstones, and sandstones, among which Member Chang 7 of the Yanchang Formation is composed of shales predominantly interbedded with silt sandstones, which is characterized by typical laminae or interbed structure (Zhang, 2006; Dong, 2012; Lei et al., 2015), and have high total organic carbon (TOC). The silty laminae structure in the continental shale plays in Ordos Basin in China leading to the extraction of shale gas is significantly different from those of marine shales documented in the USA and elsewhere (Crurtis, 2002; Tang et al., 2014). To hydraulically induce the fractures, a mixture of fracturing fluid and proppants is pumped into the formation at a very high pressure to cause rock failure. The interaction between natural fractures and hydraulic fractures is the primary production mechanism in shale gas reservoirs. The shale gas exists as free gas stored in the matrix pores and natural fractures, 
and as adsorbed gas to organic material. For the typical continental shale reservoir, according to the research results of Lei et al. (2015), the amount of free gas and solution gas in shale increases with the increase of silty laminae, and the amount of adsorbed gas decreases. Silty laminae play a significant role in free-state shale gas formation, migration, and production. Therefore, there is an urgent need to characterize continental shales and combination of horizontal drilling and multistage hydraulic fracturing technology to flourish gas production from the gas shale Yanchang formation.

To minimize the fracturing cost and environmental impacts, it is important to optimize the design of the fracturing process by understanding the parameters that affect the economic development of shale gas reservoirs (King, 2010; Boulis et al., 2013; Jahandideh and Jafarpour, 2016). Without accounting for production optimization in unconventional reservoirs, similar fracturing treatment efforts may result in different production performance (Daniels et al., 2007). Since hydraulic fracturing stimulation combined with horizontal drilling are costly and may have potential environmental influences, optimizing the fracturing parameters is crucial. Recently, some scholars have focused on opromization analysis to maximize production and minimize the fracturing cost. Jahandideh and Jafarpour (2016) applied a variant of simultaneous Perturbation Stochastic Approximation algorithm to optimized the hydraulic fracturing design by implementing maximize the net present value of the shale asset, including the cost of fracturing and the revenue from gas production. They demonstrated the effectiveness and suitability of the proposed method using a series of numerical experiments in shale gas development. Wang et al. (2016a) conducted a series of numerical simulators to reappear the evolution of fracturing network, and also using the response surface methodology to maximize the stimulated reservoir area (SRA) and stimulated laminae area (SLA) simultaneously. A total of 71 effective solutions are generated after numerical optimization. Yu and Sepehrnoori (2013) employed response surface methodology to optimize the design parameters, sucha as permeability, porosity, fracture spacing, fracture half-length, fracture con- ductivity and well distance. They reported different optimized combinations of these parameters for different gas prices. Boulis et al. (2013) applied astochastic forward modeling work flow to evaluate the optimal number of wells based on asemi-analytical shale gas. In their study, the Monte-Carlo-based stochastic modeling was used to generate alternative plausible models for forecasting production performance. Ma et al. (2013) used the Discrete Simultaneous Perturbation Stochastic Approximation (DSPSA) method and genetic algorithm (GA) to optimize hydraulic fracture placement under the spatial variability of permeability throughout the shale formation and compared the performance of the adopted methods with other methods. From the study results, they suggested that when using hybrid methods that combine the advantages of both types of algorithms is good to predict reservoir performance. Wilson and Durlofsky (2012) have applied aderivative free generalized pattern search optimization technique to determine optimal fracture location, length and number of stages based on the variability in initial reservoir pressure. The surrogate model parameters were calibrated to reproduce the predictions from a full-physics-based model. Meyer et al. (2010) presented an analytical solution for predicting the behavior of symmetric transverse hydraulic fractures for a horizontal well in a homogenous formation and used the solution to optimize the numberof fracture stages and fracture length for equally spaced fractures. Ketter et al. (2006) performed a field study optimizing completion strategies for fracture initiation in Barnett shale horizontal wells. They offer statistics on which changes have had the greatest effect on stimulation placement. Results showed that using those optimized strategies has reduced the number of stages where fracture initiation difficulties have been encountered by $74 \%$. To maximize fracture network surface area in the targeted pay intervals, and in some areas, reduce the probability of excessive fracture height growth. Fisher et al. (2004) utilized several horizontal completion techniques to understand created fracture geometry for various completion designs, fracture treatments are often mapped with microseismic and tilt sensors. Fisher et al. (2002) combined the 
microseismic analysis with surface and downhole tilt fracture mapping to understanding the created fracture geometry, and optimize the stimulations in Barnett shale. Correlations between production response and various fracture parameters have been reported along with a discussion of methods for calibrating a fracture model to the observed fracture behavior. Rickman et al. (2008) proposed a practical use of shale peterophysics for simulation design optimization. By conducting to review a laboratory database representing principal shale mineralogy and wireline log data from many of the major shale plays. The results of their study revealed some statistically significant correlations between the wireline log analysis and measured mineralogy, acid solubility, and capillary suction time test results for shale reservoirs.

From literature review, to improve the shale gas development in the southeast Ordos Basin, china, it is important to understand and characterize the multri-factors that affected the hydraulic fracturing treatment. The unprecedented growth of shale reservoirs has brought a new perspective and focus on the optimization of multiple hydraulically fractured parameters in silty laminae shales. How to maximize the total stimulated reservoir volume plays a major role in successful economic gas production for shale gas (King, 2010; Meyer et al., 2010; Wang et al., 2015, 2016b). In this paper, a coupled model for heterogeneous geomaterials taking into account fluid flow, element damage evolution and their cross-coupling was integrated to simulate the fracturing network propagation. D-Optimal design was adopted to design the experiment, and the response surface methodology is employed to build the response surface in terms of stimulated reservoir area (SRA) with seven parameters, such as three silty laminae structural parameters (thickness, spacing, dip angle), two geomechanical parameters (internal friction angle, cohesion), one in-situ field stress parameter (stress difference) and one operational parameter (injection rate) to obtain the best economic scenario for a given range of these influential parameters. The study described in this paper aims to investigate the factors influencing the fracturing network propagation based on numerical modeling and optimization algorithm, and also evaluate the fracability of the Yanchang gas field in the southeast China.

\section{Hydraulic Fracturing Model Setup}

In shale fracturing, one of the challenges that influence the stimulation and productivity predication is the heterogeneity of reservoirs (King, 2010; Wang et al., 2015, 2016b). Firstly, the rock matrix is composed of many different kinds of mineral, crystal grain, pores and miro-cracks etc. from the perspective of mesoscopic. Secondly, the natural fractures are greatly developed in natural reservoirs from macro perspective. Some parts of very anisotropic rocks fracture at a much lower pressure than other parts, thus the frac will have a preferential path through the shale fabric (Warpinski, 1987). The impact of anisotropic rock fabric and the flow paths that they create is one of the major unknowns for any shale. Even fracs on shale with extensive natural fracture systems have shown preferential fracture development that is traceable from well to well. The naturally fractured formations under hydraulic loading exhibit a unique feature: the flow and transport behavior within developing fractures are dramatically different from those in rocks with existing fractures under the same loading. The permeability of rocks with existing fractures does not change, but it can change dramatically due to damage evolution in fracturing rocks. The influence of damage on the variation of permeability as well as the original nature of the existing fractures in reservoirs is critical to shear stimulation of natural fractures. Another major problem in characterizing the hydraulic behavior of reservoirs concerns the irregular flow paths that depend on the mechanical heterogeneity of the formations. In working with heterogeneous formations, a key factor is to determine the specific data that are needed to ascertain the effect of heterogeneity on the complicated flow paths in the fracturing formations. To solve the coupled 
flow-damage problems, Tang (2002) proposed a flow-stress-damage (FSD) coupling model of by taking into account the growth of existing fractures and the formation of induced fractures. This FSD model can be used to trace the development of fractures and the associated fluid flow, and to simulate the overall response of rock mass arising from the fracturing process under hydraulic and boundary loadings.

2.1 Brief description of the model

Numerical simulation is currently one of the most popular and effective approachs used for investigating and stimulating the hydraulic fracturing behaviors of gas shale formation. RFPA-Flow code is a numerical simulation tool using finite element analysis to handle the progressive failure of heterogeneous, permeable rock. In the model, the coupled effects of flow, stress and damage on the extension of existing/new fractures and the permeability change due to damage evolution of the rocks were addressed. This coupled flow, stresses and damage (FSD) model in RFPA-Flow has been validated in the previous publications (Tang et al. 2002; Wang et al., 2015, 2016). There are two features distinguishing RFPA-Flow from other numerical approaches: (1)by introducing heterogeneity of rock properties into the model, the RFPA-Flow code can simulate non-linear deformation of a quasi-brittle behavior with an ideal brittle constitutive law for the local material; (2)by introducing a reduction of material parameters after element failure, the RFPA code can simulate strain-softening and discontinuous mechanics problems in a continuum mechanics mode. For heterogeneity, the material properties (failure-strength $\sigma_{c}$ and elastic modulus $E_{c}$ ) for elements are randomly distributed throughout the model by following a Welibull distribution:

$$
\varphi=\frac{m}{\sigma_{0}}\left(\frac{\sigma}{\sigma_{0}}\right)^{m-1} \exp \left[-\left(\frac{\sigma}{\sigma_{0}}\right)^{m}\right]
$$

Where $\sigma$ is the element strength and $\sigma_{0}$ is the mean strength of the elements for the specimen. For an elastic modulus, $\mathrm{E}$, the same distribution is used. We define $m$ as the homogeneity index of the rock (Tang, 2002). According to the definition, a larger $m$ implies a more homogeneous material and vice versa.

This FSD model is different from the finite element modeling and distinct element modeling. The most unique feature of this code, which makes it totally different from other kind of numerical code in hydraulic fracturing, is that it can simulate the whole shear stimulated process of pre-existing fractures and their interaction with hydraulic fractures in hydraulic fracturing. In the model, the initiation, propagation of natural fractures are dynamic not static, the interaction behaviors (cross, offset and capture) of hydraulic fracture and natural fracture are automatic accomplished according to the mechanical characteristics.

\subsection{RFPA-Flow model setup}

The outcrop observation and core measurement indicated that laminae are sound developed in the producing shales. From the core statistical results of Zhangjiatan Shale, southeastern Ordos Basin, the laminae thickness ranges from 0.2 to $4 \mathrm{~mm}$, and is $1.5 \mathrm{~mm}$ on average; the frequency ranges from 4 to 32 laminae $/ \mathrm{m}$ and is laminae/m on average. The thickness percentage of silty laminae in the measured segments ranges from 6 to 17\% (Lei et al., 2015). By measuring the typical core sample of Chang 7 wells, we found that thickness of silty laminae ranges from 0.5 to $6 \mathrm{~mm}$ (Fig.1). Silty laminae was extremely heterogeneous, and composed of quartz, feldspar, mixed-layer montmorillonite, and chlorite, its mechanical properties are controlled by the micro heterogeneity characteristics of these minerals.

Fig. 2 shows the geometry and boundary conditions of the studied model. The model represents a 2D horizontal section of a reservoir. In the model, the injection is through a vertical wellbore in the center of the model, the increasing injection pressure was imposed on the wellbore at constant rate. The whole model is composed of $40000(200 \times 200)$ identical square elements with dimension of $200 \mathrm{~mm} \times 200 \mathrm{~mm}$.

The diameter of the injection hole was $15 \mathrm{~mm}$. For all the simulations, the maximum horizontal stress $(\sigma$ 
H) was $20 \mathrm{MPa}$, the minimum horizontal stress $\left(\sigma_{h}\right)$ was $15 \mathrm{MPa}$. The initial pore pressure $\left(\mathrm{P}_{0}\right)$ was set to $10 \mathrm{MPa}$. The input material mechanical parameters for the numerical models are referred to Wang (2013), as shown in Table 1. For all the simulations, the slick-water-frac treatment is selected during the simulations, fluid rheology is $1 \mathrm{cp}$.

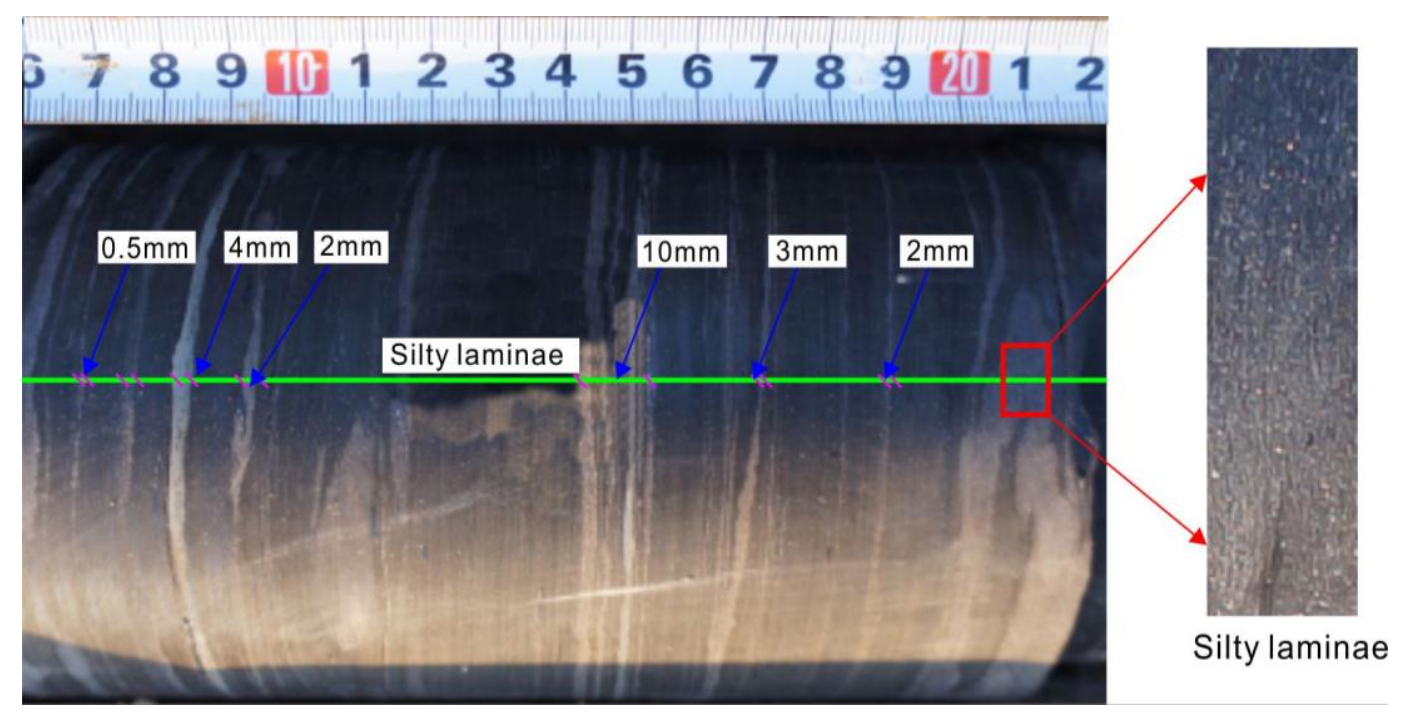

Fig.1 The typical shale core with silty laminae from Chang 7 member, Ordos basin

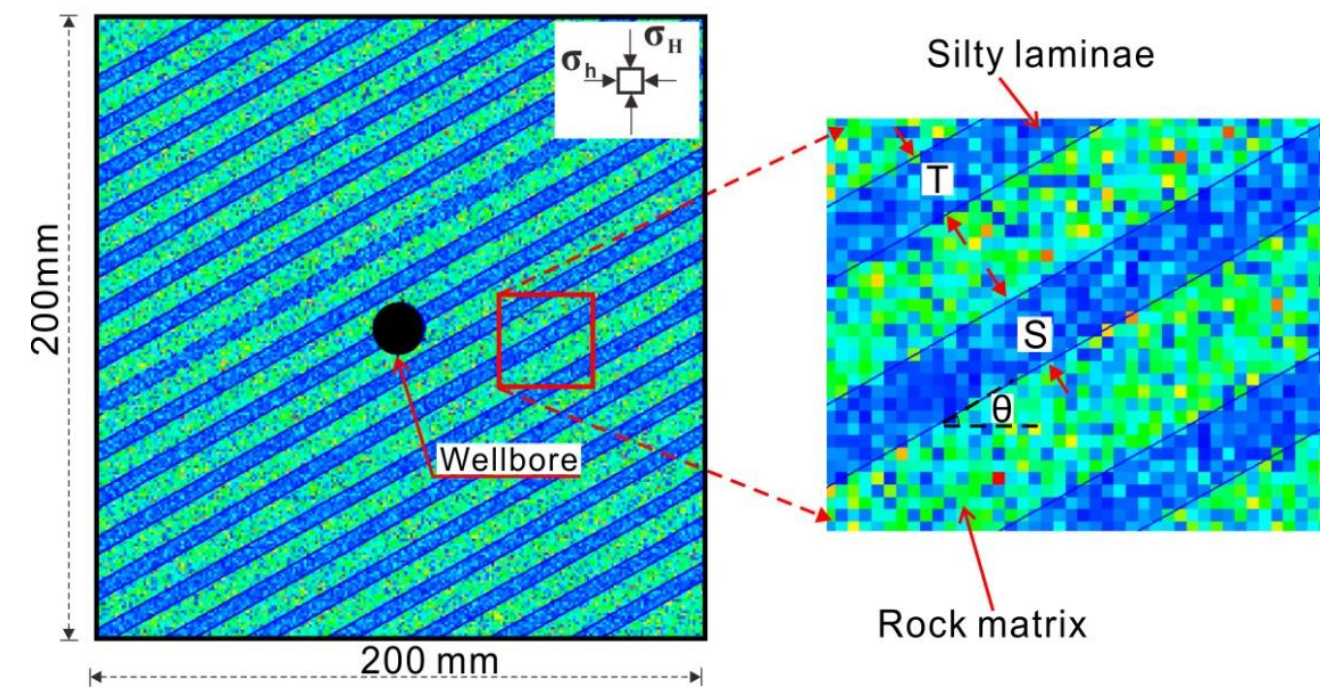

Fig.2 Nuermical model of the continental shale reserivor with silty laminae in this study

Table 1 Parameters used in multi-parameter optimization

\begin{tabular}{|c|c|c|c|}
\hline Parameter & Rock matrix & Silty laminae & Unit \\
\hline Homogeneity index (m) & 2 & 2 & \\
\hline Elastic modulus (E0) & 60 & 30 & $\mathrm{GPa}$ \\
\hline Poisson's ratio(v) & 0.2 & 0.3 & \\
\hline Internal friction angle $(\varphi)$ & 53 & l & $\circ$ \\
\hline Compressive strength( $\sigma c)$ & 330 & l & $\mathrm{MPa}$ \\
\hline Tensile strength( $\sigma t)$ & 33 & I & $\mathrm{MPa}$ \\
\hline Coefficient of residual strength & 0.1 & 0.1 & \\
\hline Permeability coefficient (k0) & 0.0002 & 0.002 & $\mathrm{mD}$ \\
\hline Porosity & 0.06 & 0.072 & \\
\hline
\end{tabular}




$\begin{array}{lll}\text { Coupling coefficient }(\beta) & 0.01 & 0.01 \\ \text { Coefficient of pore-water pressure }(\alpha) & 0.6 & 0.6\end{array}$

\section{Multiparameter Optimization}

\subsection{D-Optimal design}

Response surface methodology (RSM) approach is applied to the optimization of the index SRA. RSM is utilized to approximate a response, in terms of maximum SRA, over a region of interest specified by the range of variability of input factors based on the least squares criterion. The RSM model can be linear or fully quadratic. It can offer a cost-effective and efficient way to manage the uncertainties for shale gas reservoir development. More detailed mathematical and statistical theories of RSM can be found in the work by Myers and Montgomery (2002). The shale gas reservoir model is shown in Fig.2. Seven uncertain parameters such as thickness $(T)$, spacing $(S)$, dip angle $(\theta)$, laminae friction angle (FAI), laminae cohesion (C), stress difference (SD) and injection rate (IR) are given a reasonable range with the actual maximum and minimum values or coded symbol of " +1 " and " -1 ," respectively, as shown in Table 2. For the convenience of numerical model built up, and discuss the influence of thickness on fracturing effectiveness, the minimum thickness is set as $2 \mathrm{~mm}$. According to 7 variables, 46 cases were required, based on the approach of D-Optimal design, which was originated from the optimal design theory (Kiefer and Wolfowitz, 1959). Table 3 shows the 46 combinations of these uncertain parameters generated by the D-Optimal design. After the numerical simulation of each case, results of hydraulic fracturing are shown in Fig. 5 for partial selected cases with various designs in Table 3 . In order to qualitatively evaluate the effect of hydraulic fracturing, the model responses are compared using an index of stimulated reservoir area (SRA), which is defined as the interaction area of hydraulic fractures and silty laminae that has experienced a fluid pressure increase due to injection, SRA is the overall reflection of hydraulic fracturing effectiveness. As there is no precise criteria for defining the stimulated reservoir area, a criteria based on fracture pressure change was employed in this work. The interaction area of hydraulic fractures and silty laminae having a pore pressure increament below the maximum value of $5 \mathrm{MPa}$ was considered as SRA, it refers to the "red" region in Fig.3a. Fig.4 plots the progressive fracturing process for case 14. It can be shown that initiation of hydraulic fracture occurs from silty laminae, and fracturing network propagates with the increasing of injection step. The interaction between silty laminae and hydraulic fracture becomes severe with the continuous injected fluid and the high leak off region increase during the hydraulic fracturing process. The red region around the wellbore indicates the high leak off region; the pore pressure is relative higher than other region in the whole model.

Table 2 Uncertainty parameters of multiple parameter optimizations in this study

\begin{tabular}{ccccc}
\hline Parameters & Coded symbol & Maximum $(+1)$ & Minimum $(-1)$ & Unit \\
\hline Thickness & A & 6 & 2 & $\mathrm{~mm}$ \\
Spacing & B & 8 & 2 & $\mathrm{~mm}$ \\
Dip angle & C & 60 & 0 & $\circ$ \\
Cohesion & D & 30 & 10 & $\mathrm{MPa}$ \\
Friction angle & $\mathrm{E}$ & 40 & 20 & $\circ$ \\
Stress difference & $\mathrm{F}$ & 5 & 0 & $\mathrm{MPa}$ \\
Injection rate & $\mathrm{G}$ & 0.02 & 0.008 & $\mathrm{~m} 3 / \mathrm{d} / \mathrm{m}$ \\
\hline
\end{tabular}



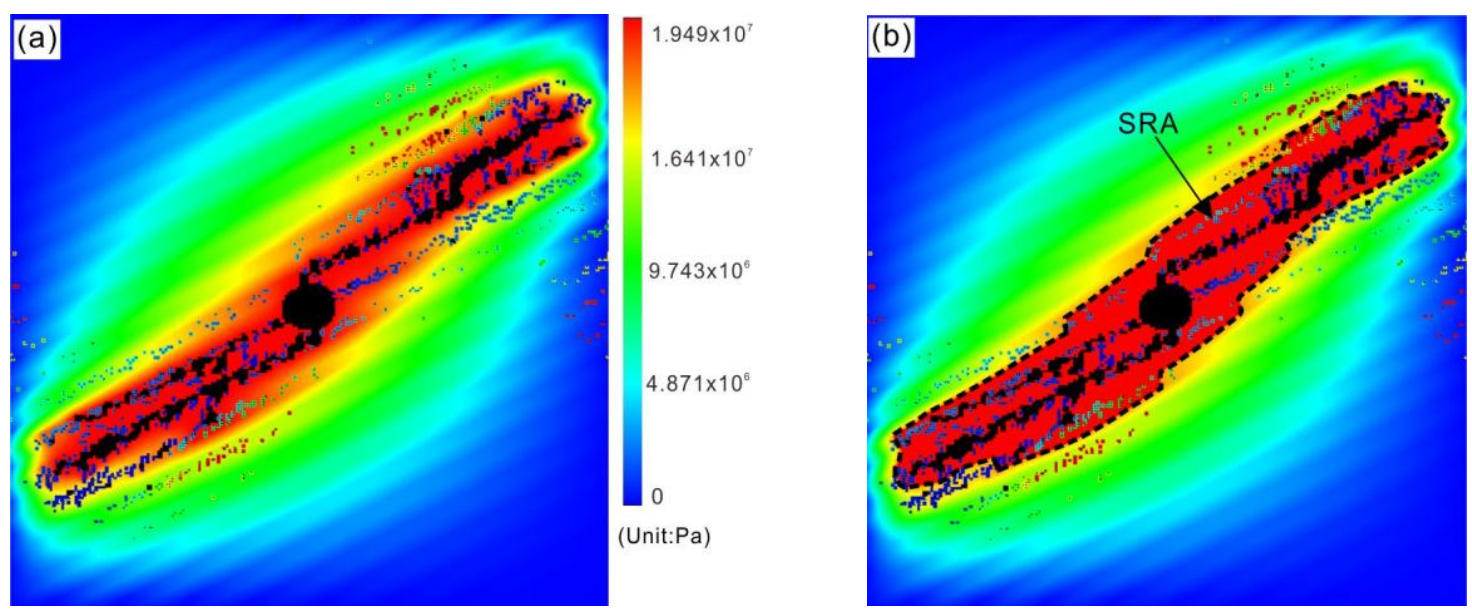

Fig.3 Determination of SRA based on gray segmentation for case 12 (a. The numerical results of cas 14, the color shadow indicates relative magnitude of the pore pressure field. (b) Determination of SRA using digital image process, SRA is the overall reflection of hydraulic fracturing effectiveness)

Table 3 D-Optimal design table for the fracturing network propagation

\begin{tabular}{|c|c|c|c|c|c|c|c|c|}
\hline Run & $\begin{array}{l}\text { A-Thinkness } \\
(\mathrm{mm})\end{array}$ & $\begin{array}{l}\text { B-Spacing } \\
(\mathrm{mm})\end{array}$ & $\begin{array}{c}\text { C-Angle } \\
\left({ }^{\circ}\right)\end{array}$ & $\begin{array}{l}\text { D-Cohesion } \\
\quad(\mathrm{MPa})\end{array}$ & $\begin{array}{c}\text { E-IFA } \\
\left(^{\circ}\right)\end{array}$ & F-SD & $\begin{array}{c}\text { G-IR } \\
\left(\mathrm{m}^{3} / \mathrm{d} / \mathrm{m}\right)\end{array}$ & $\begin{array}{l}\text { R-SRA } \\
\left(\mathrm{mm}^{2}\right)\end{array}$ \\
\hline 1 & 6 & 2 & 0 & 30 & 20 & 0.000 & 0.02 & 4850 \\
\hline 2 & 6 & 8 & 0 & 10 & 20 & 0.000 & 0.02 & 3504 \\
\hline 3 & 5 & 2 & 0 & 10 & 40 & 5.000 & 0.008 & 3501 \\
\hline 4 & 6 & 6 & 60 & 10 & 40 & 0.000 & 0.008 & 4635 \\
\hline 5 & 2 & 8 & 60 & 10 & 20 & 5.000 & 0.02 & 3520 \\
\hline 6 & 6 & 3 & 60 & 30 & 20 & 3.998 & 0.008 & 2155 \\
\hline 7 & 4 & 4 & 0 & 10 & 29 & 0.000 & 0.014 & 4653 \\
\hline 8 & 2 & 2 & 60 & 10 & 34 & 5.000 & 0.008 & 3007 \\
\hline 9 & 2 & 2 & 60 & 30 & 40 & 0.000 & 0.02 & 7798 \\
\hline 10 & 6 & 8 & 60 & 10 & 40 & 5.000 & 0.02 & 3147 \\
\hline 11 & 6 & 2 & 0 & 10 & 20 & 0.000 & 0.008 & 2892 \\
\hline 12 & 4 & 6 & 27 & 30 & 40 & 2.193 & 0.02 & 6661 \\
\hline 13 & 4 & 2 & 60 & 30 & 20 & 5.000 & 0.02 & 4694 \\
\hline 14 & 2 & 8 & 0 & 30 & 20 & 5.000 & 0.02 & 5957 \\
\hline 15 & 4 & 2 & 60 & 21 & 31 & 0.000 & 0.008 & 4886 \\
\hline 16 & 6 & 2 & 0 & 30 & 40 & 5.000 & 0.02 & 7356 \\
\hline 17 & 2 & 8 & 0 & 10 & 40 & 0.000 & 0.02 & 5715 \\
\hline 18 & 6 & 6 & 0 & 30 & 20 & 5.000 & 0.008 & 4842 \\
\hline 19 & 2 & 2 & 60 & 10 & 20 & 0.000 & 0.02 & 5944 \\
\hline 20 & 2 & 8 & 0 & 10 & 20 & 5.000 & 0.008 & 2066 \\
\hline 21 & 3 & 2 & 56 & 18 & 40 & 5.000 & 0.02 & 4978 \\
\hline 22 & 6 & 2 & 34 & 10 & 20 & 5.000 & 0.012 & 5032 \\
\hline 23 & 6 & 8 & 60 & 30 & 28 & 0.000 & 0.02 & 4568 \\
\hline 24 & 2 & 8 & 60 & 30 & 22 & 5.000 & 0.012 & 5351 \\
\hline 25 & 6 & 2 & 0 & 10 & 40 & 0.000 & 0.02 & 4668 \\
\hline 26 & 6 & 8 & 0 & 26 & 40 & 0.000 & 0.014 & 3659 \\
\hline 27 & 6 & 8 & 0 & 10 & 20 & 0.000 & 0.02 & 2977 \\
\hline 28 & 5 & 8 & 29 & 30 & 20 & 0.000 & 0.008 & 3247 \\
\hline
\end{tabular}




\begin{tabular}{lllllllll}
29 & 5 & 2 & 0 & 10 & 40 & 5.000 & 0.008 & 5683 \\
30 & 2 & 8 & 0 & 30 & 40 & 0.000 & 0.008 & 3145 \\
31 & 2 & 6 & 0 & 20 & 20 & 0.000 & 0.008 & 3863 \\
32 & 6 & 2 & 34 & 10 & 20 & 5.000 & 0.012 & 4543 \\
33 & 6 & 2 & 60 & 30 & 40 & 2.448 & 0.012 & 4945 \\
34 & 6 & 8 & 17 & 10 & 33 & 2.515 & 0.008 & 2408 \\
35 & 6 & 8 & 60 & 10 & 20 & 3.246 & 0.008 & 2376 \\
36 & 2 & 2 & 0 & 10 & 20 & 5.000 & 0.02 & 5513 \\
37 & 2 & 5 & 0 & 20 & 40 & 5.000 & 0.014 & 6770 \\
38 & 2 & 2 & 0 & 30 & 20 & 5.000 & 0.008 & 4975 \\
39 & 2 & 2 & 18 & 10 & 40 & 0.000 & 0.008 & 3694 \\
40 & 2 & 8 & 60 & 10 & 20 & 0.000 & 0.008 & 3834 \\
41 & 6 & 2 & 0 & 30 & 38 & 0.000 & 0.008 & 3783 \\
42 & 2 & 8 & 60 & 18 & 40 & 1.375 & 0.0128 & 6993 \\
43 & 6 & 8 & 60 & 30 & 40 & 5.000 & 0.008 & 3356 \\
44 & 4 & 6 & 27 & 30 & 40 & 2.193 & 0.02 & 7426 \\
45 & 6 & 2 & 0 & 10 & 20 & 0.000 & 0.008 & 2534 \\
46 & 2 & 3 & 60 & 30 & 20 & 0.000 & 0.008 & 3659 \\
\hline
\end{tabular}
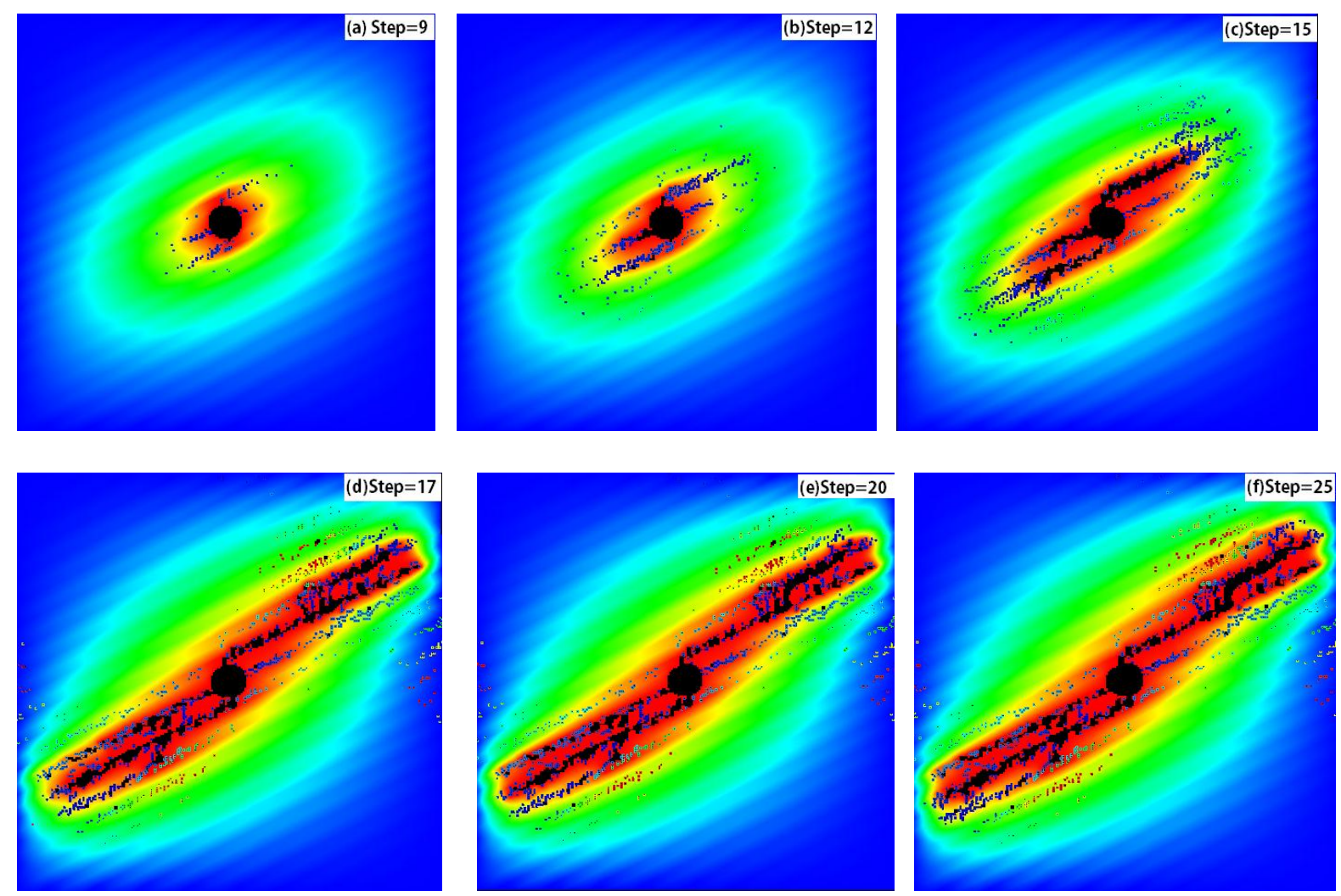

Fig.4 The interaction process between silty laminae and hydraulic fractures for case 12 in Table 3, the color shadow indicates relative magnitude of the pore pressure field. 

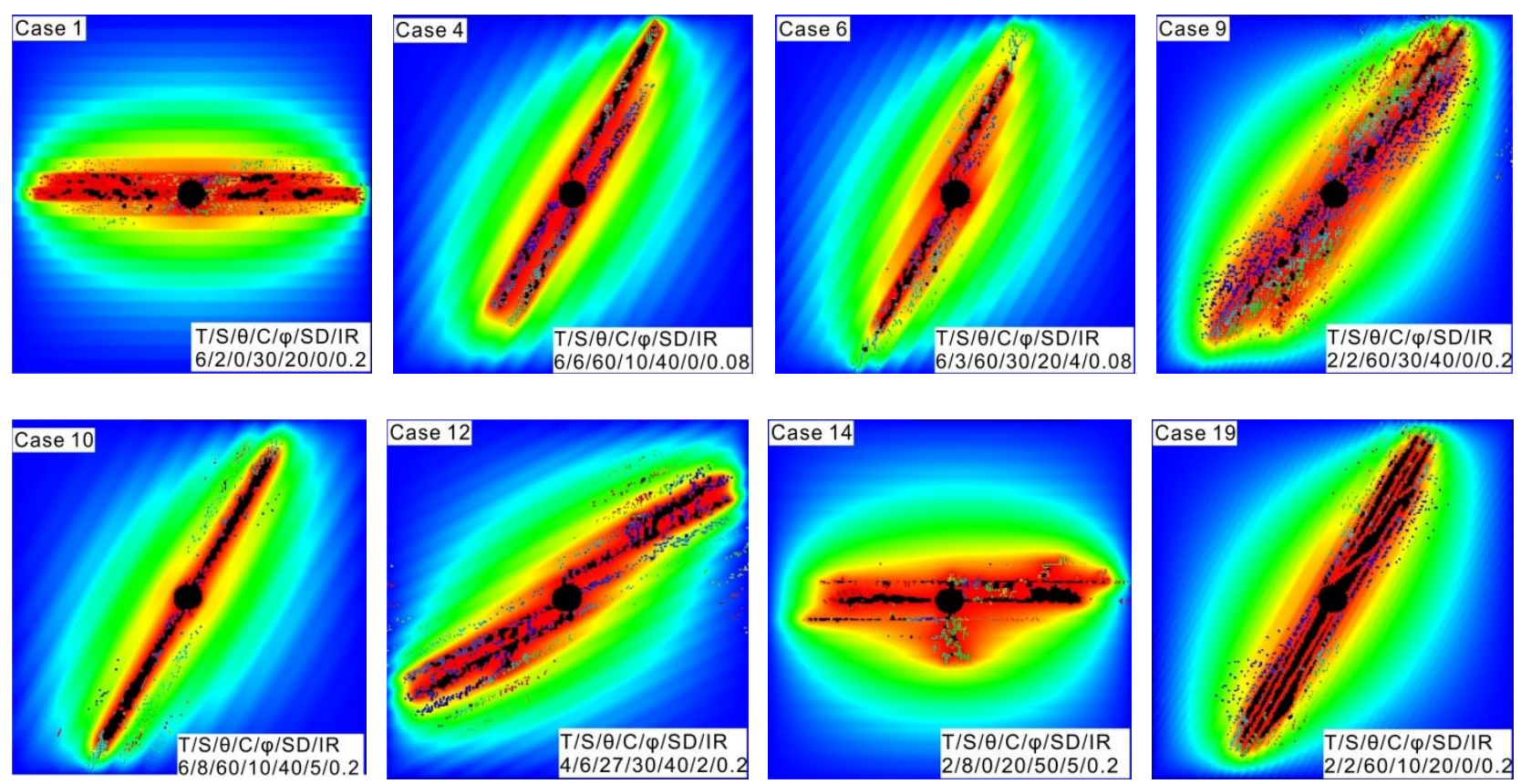

Fig. 5 The hydraulic fracturing simulation results for the partial 8 run cases according to Table 3

\subsection{RSM model analysis}

According to the designed cases mentioned above, the purpose of the RSM model is to obtain the maximum stimulated reservoir area. Therefore, SRA is considered optimization of fracturing design in multi-parameter to determine the optimal stimulation design. Once the maximum stimulated area of 46 run cases obtained, the RSM method is used to analyze the relationship between the response value and influential factors. To select the appropriate model, the statistical approach was used to determine which polynomial fit the equation with a linear model, two factor model interaction model (2FI), quadratic model, or cubic model, as shown in Table 4. The criterion for selecting the appropriate model is choosing the highest polynomial model, where the additional terms are significant and the model is not aliased. Although the cubic model is the highest polynomial model, it is not selected because is it aliased. Aliasing is a result of reducing the number of experimental runs. When it occurs, several groups of effects are combined into one group and the most significant effect in the group is used to represent the effect of the group. Essentially, it is important that the model is not aliased. In addition, other criteria are needed to select the model that has the maximum "Adjusted R-Squared" and "Predicted R-Squared". Thus, the fully quadratic model and linear model is selected to build the SRA response surface in the subsequent optimization process, respectively.

Table 4 Statistical approach to select the RSM model for SRA

\begin{tabular}{ccccccc}
\hline Source & Std.Dev & R-Squared & $\begin{array}{c}\text { Adjusted } \\
\text { R-Squared }\end{array}$ & $\begin{array}{c}\text { Predicted } \\
\text { R-Squared }\end{array}$ & Press & \\
\hline Linear & 1015.09 & 0.575 & 0.497 & 0.372 & $5.784 \mathrm{E}+007$ & - \\
2FI & 802.82 & 0.881 & 0.685 & 0.106 & $1.019 \mathrm{E}+008$ & - \\
Quadratic & 751.97 & 0.979 & 0.724 & 0.681 & $3.114 \mathrm{E}+008$ & Suggested \\
Cubic & 736.23 & 0.911 & 0.735 & $/$ &, & Aliased \\
\hline
\end{tabular}

The anova for response surface quadratic model of SRA is shown in Table 5 . The model F-value of 4.37 implies the model is significant. There is only a $0.86 \%$ chance that a "Model F-Value" this large could occur due to noise. Values of "Prob > F" less than 0.05 indicates the model terms are significant. In this case, factor of $A, D, E$, and $G$, are significant model terms. The influential order of these seven factors is: G-injection rate> A-thickness > D-Cohesion> E-Friction angle> C-Dip angle> B-Spacing> 
F-Stress difference.

Table 5 Anova for SRA response surface with quadratic model

\begin{tabular}{|c|c|c|c|c|c|c|}
\hline Source & $\begin{array}{l}\text { Sum of } \\
\text { Squares }\end{array}$ & df & $\begin{array}{l}\text { Mean } \\
\text { Square }\end{array}$ & $\begin{array}{l}\text { F } \\
\text { Value }\end{array}$ & $\begin{array}{l}\mathrm{p} \text {-value } \\
\text { Prob > F }\end{array}$ & \\
\hline Model & 86450363 & 35 & 2470010.01 & 4.368127 & 0.0086 & significant \\
\hline A-Thickness & 8459177 & 1 & 8459177.13 & 14.95976 & 0.0031 & \\
\hline B-Spacing & 1716999 & 1 & 1716999.05 & 3.036452 & 0.1120 & \\
\hline C-Dip angle & 129921.3 & 1 & 129921.32 & 0.229761 & 0.6420 & \\
\hline D-Cohesion & 7771839 & 1 & 7771839.11 & 13.74423 & 0.0041 & \\
\hline E-Friction angle & 3932959 & 1 & 3932959.23 & 6.9553 & 0.0248 & \\
\hline F-Stress difference & 11024.26 & 1 & 11024.26 & 0.019496 & 0.8917 & \\
\hline G-Injection rate & 16222092 & 1 & 16222092 & 28.68821 & 0.0003 & \\
\hline $\mathrm{AB}$ & 908982.6 & 1 & 908982.60 & 1.607504 & 0.2336 & \\
\hline$A C$ & 969229.2 & 1 & 969229.21 & 1.714048 & 0.2197 & \\
\hline$A D$ & 886160.1 & 1 & 886160.11 & 1.567143 & 0.2391 & \\
\hline$A E$ & 110790.7 & 1 & 110790.71 & 0.195929 & 0.6674 & \\
\hline$A F$ & 1285135 & 1 & 1285135.00 & 2.272717 & 0.1626 & \\
\hline$A G$ & 2279676 & 1 & 2279676.00 & 4.031527 & 0.0724 & \\
\hline $\mathrm{BC}$ & 4005995 & 1 & 4005995.00 & 7.084462 & 0.0238 & \\
\hline $\mathrm{BD}$ & 74418.67 & 1 & 74418.67 & 0.131607 & 0.7243 & \\
\hline $\mathrm{BE}$ & 35792.71 & 1 & 35792.71 & 0.063298 & 0.8065 & \\
\hline BF & 329332.1 & 1 & 329332.12 & 0.582412 & 0.4630 & \\
\hline$B G$ & 1658.835 & 1 & 1658.84 & 0.002934 & 0.9579 & \\
\hline CD & 476332.1 & 1 & 476332.13 & 0.842377 & 0.3803 & \\
\hline CE & 834215.7 & 1 & 834215.72 & 1.475281 & 0.2524 & \\
\hline CF & 6647255 & 1 & 6647255.01 & 11.75544 & 0.0065 & \\
\hline CG & 876165 & 1 & 876165.02 & 1.549467 & 0.2416 & \\
\hline DE & 294504.4 & 1 & 294504.41 & 0.520821 & 0.4870 & \\
\hline DF & 1004197 & 1 & 1004197.03 & 1.775888 & 0.2122 & \\
\hline DG & 247794.8 & 1 & 247794.81 & 0.438217 & 0.5229 & \\
\hline EF & 223149.7 & 1 & 223149.70 & 0.394632 & 0.5440 & \\
\hline$E G$ & 72496.46 & 1 & 72496.46 & 0.128207 & 0.7277 & \\
\hline$F G$ & 599324.3 & 1 & 599324.31 & 1.059884 & 0.3275 & \\
\hline$A^{\wedge} 2$ & 215653.1 & 1 & 215653.10 & 0.381375 & 0.5507 & \\
\hline$B^{\wedge} 2$ & 515431.8 & 1 & 515431.80 & 0.911523 & 0.3622 & \\
\hline $\mathrm{C}^{\wedge} 2$ & 364493.1 & 1 & 364493.12 & 0.644593 & 0.4407 & \\
\hline$D^{\wedge} 2$ & 900326.8 & 1 & 900326.82 & 1.592197 & 0.2356 & \\
\hline$E^{\wedge} 2$ & 68202.44 & 1 & 68202.44 & 0.120614 & 0.7356 & \\
\hline$F^{\wedge} 2$ & 101261.9 & 1 & 101261.90 & 0.179078 & 0.6811 & \\
\hline$G^{\wedge} 2$ & 638668.4 & 1 & 638668.43 & 1.129463 & 0.3129 & \\
\hline Residual & 5654621 & 10 & 565462.14 & & & \\
\hline Lack of Fit & 2944413 & 5 & 588882.74 & 1.086416 & 0.4649 & not significant \\
\hline Pure Error & 2710208 & 5 & 542041.51 & & & \\
\hline Cor Total & 92104984 & 45 & & & & \\
\hline
\end{tabular}

From Table 5, it can be seen that the operational parameter of the injection rate is the most sensitive factor to the models. This indicates that injection rate is crucial to hydraulic fracturing effectiveness. This conclusion is consistent with King (2010), Nagel et al., (2011) and Wang et al., (2016). With low injection rate, fluid is prone to leak into the pre-existing discontinuities despite the influence of the fluid pressure; 
and once the injected fluid leaks into the discontinuities, the pressure can rise far above the confining stress without inducing new hydraulic fractures. With large injection rate, the hydraulic fracture tends to cross the natural fracture due to the increase of the pressurization rate. In addition, the factor $\mathrm{A}$ (thickness) is also sensitive to SRA. Mechanical properties of silty laminae is weaker than shale matrix, its thickness affacts the propagation region of stimulated reservoir area.

The equations fitted to the SRA response surface with coded symbol are presented below. $\mathrm{SRA}=+5933.64-442.45 \times \mathrm{A}-253.86 \times \mathrm{B}-32.55 \times \mathrm{C}+873.64 \times \mathrm{D}+334.67 \times \mathrm{E}-25.34 \times \mathrm{F}+873.32 \times$ $\mathrm{G}-234.64 \times \mathrm{A} \times \mathrm{B}-265.21 \times \mathrm{A} \times \mathrm{C}-200.43 \times \mathrm{A} \times \mathrm{D}-58.98 \times \mathrm{A} \times \mathrm{E}+290.13 \times \mathrm{A} \times \mathrm{F}-323.15 \times \mathrm{A} \times \mathrm{G}+466.55 \times \mathrm{B}$ $\times \mathrm{C}-61.14 \times \mathrm{B} \times \mathrm{D}-44.23 \times \mathrm{B} \times \mathrm{E}-134.05 \times \mathrm{B} \times \mathrm{F}+7.27 \times \mathrm{B} \times \mathrm{G}-141.76 \times \mathrm{C} \times \mathrm{D}+189.63 \times \mathrm{C} \times \mathrm{E}-534.23 \times$ $\mathrm{C} \times \mathrm{F}-192.32 \times \mathrm{C} \times \mathrm{G}+111.33 \times \mathrm{D} \times \mathrm{E}+196.15 \times \mathrm{D} \times \mathrm{F}+89.86 \times \mathrm{D} \times \mathrm{G}-112.32 \times \mathrm{E} \times \mathrm{F}-54.36 \times \mathrm{E} \times$ $\mathrm{G}-181.56 \times \mathrm{F} \times \mathrm{G}-234.56 \times \mathrm{A}^{\wedge} 2-377.34 \times \mathrm{B}^{\wedge} 2-401.25 \times \mathrm{C}^{\wedge} 2-653.38 \times \mathrm{D}^{\wedge} 2-156.07 \times \mathrm{E}^{\wedge} 2+234.01 \times$ $F^{\wedge} 2-434.66 \times G^{\wedge} 2$

Where $A$ is laminae thickness; $B$ is laminae length; $C$ is laminae dip angle; $D$ is laminae cohesion; $E$ is laminae internal friction angle; $F$ is in situ stress difference $\left(\sigma_{H}-\sigma_{h}\right)$, and $G$ is injection rate.

The normal plot of residuals, reflecting the distribution of the residuals, for SRA is shown in Fig.6a. All the points in the "Normal Plot of Residuals" fall on the straight line, meaning the residuals are normally distributed. Fig.6b shows the plot of "Predicted versus Actual" for SRA, illustrating whether the generated equation of stimulated area response surface accurately predicts the actual SRA values. It can be seen that generated SRA response surface models provide such reliable predicted values of SRA, as compared with the actual values of SRA. This means that the generated SRA response surface models are reliable.
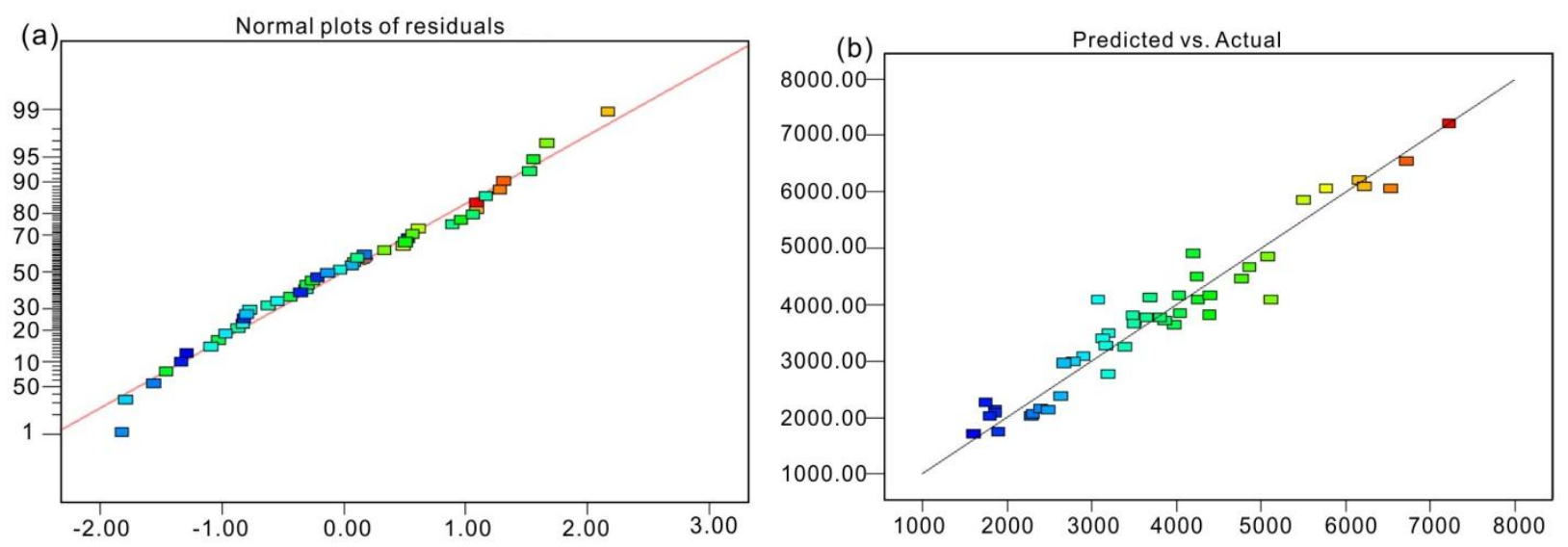

Fig.6 Verification of the RSM model for SRA. (b) Normal plot of residuals for SRA; and (b) the predicted stimulated area versus the actual stimulated area plot for SRA

Fig. 7 shows the 3D surface of the influential factors for SRA, the response surface represents a run case among the 46 cases. It shows the influential tread of the seven factors to SRA. In Fig.7a, SRA decreases with the increase of thickness, and increases with the increase of spacing. Fig.7b shows the influence of spacing and dip angle on SRA, and SRA increases with increasing spacing. Fig.7c shows the influence of cohesion and friction angle on SRA, and SRA increases with increasing cohesion and friction angle. Fig.7d shows the relationship of stress difference, injection rate and SRA, SRA increases with increasing of injection rate and decreasing stress difference. It can be seen that large injection rate, cohesion and friction angle, can lead to the increasing of SRA. This can be better interpreted that with larger cohesion and friction angle, the strength of silty laminae is higher; during hydraulic fracturing, leak 
off is relative lower into laminae, and the injected fluid is mainly used to communicate silty laminae and shale matrix.
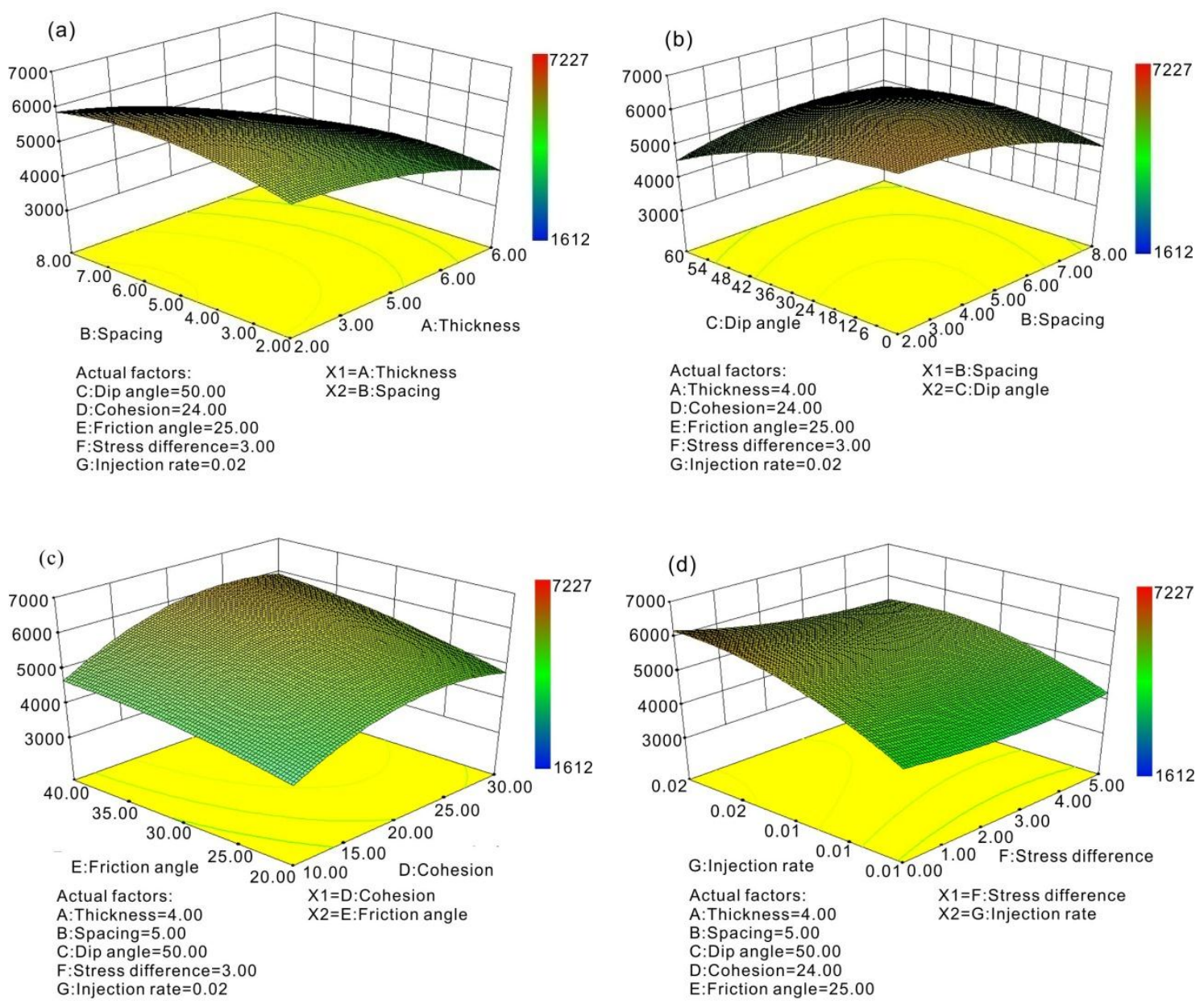

Fig.7 The influential of studied factors on SRA response surface (a. influence of lanimae friction angle and thickness on SRA; b. influence of lanimae dip angle and spacing on SRA; c. influence of lanimae friction angle and cohesion on SRA; $d$. influence of injection rate and stress difference on SRA)

\subsection{Maximum SRA optimization and solutions}

The index of SRA reflects the overall response of the formation subjected to hydraulic fracturing, the larger the index, the better the fracturing network is. This index is very important to shale gas productivity in silty laminae formations, southeastern Ordos Basin, China. In this work, the numerical optimization using response surface method was done to select the set of variables that leads to the maximum SRA. A total of 71 optimal projects can be generated after numerically optimization. Table 8 lists the top 15 solutions to obtain the maximum SRA. Fig.8 shows the effects of structural parameter, mechanical properties, in-situ stress filed, and injection rate, on the desirable solutions of SRA.

Table 8 Optimal combinations and optimization validation for SRA

\begin{tabular}{ccccccccc}
\hline Number & $\begin{array}{c}\text { A-Thinkness } \\
(\mathrm{mm})\end{array}$ & $\begin{array}{c}\text { B-Spacing } \\
(\mathrm{mm})\end{array}$ & $\begin{array}{c}\text { C-Angle } \\
\left({ }^{\circ}\right)\end{array}$ & $\begin{array}{c}\text { D-Cohesion } \\
(\mathrm{MPa})\end{array}$ & $\begin{array}{c}\text { E-IFA } \\
\left({ }^{\circ}\right)\end{array}$ & $\begin{array}{c}\text { F-SD } \\
(/)\end{array}$ & $\begin{array}{c}\text { G-IR } \\
\left(\mathrm{m}^{3} / \mathrm{d} / \mathrm{m}^{2}\right)\end{array}$ & $\begin{array}{c}\text { R-SRA } \\
\left(\mathrm{mm}^{2}\right)\end{array}$ \\
\hline 1 & 2.04 & 2.56 & 19.10 & 29.17 & 37.77 & 4.99 & 0.02 & 7274.59 \\
2 & 2.51 & 3.70 & 32.10 & 24.14 & 36.68 & 0.91 & 0.02 & 7254.88 \\
3 & 2.62 & 3.79 & 36.00 & 26.22 & 33.53 & 0.10 & 0.02 & 7258.49 \\
4 & 2.00 & 2.69 & 21.78 & 27.08 & 40.00 & 2.47 & 0.02 & 7227.13 \\
5 & 2.01 & 4.28 & 10.83 & 28.70 & 39.97 & 3.31 & 0.02 & 7230.68
\end{tabular}




\begin{tabular}{ccccccccc}
6 & 2.44 & 5.59 & 19.36 & 24.09 & 38.71 & 0.14 & 0.02 & 7349.67 \\
7 & 2.34 & 6.58 & 23.07 & 26.68 & 38.51 & 0.32 & 0.02 & 7248.94 \\
8 & 2.98 & 2.14 & 4.01 & 28.36 & 36.33 & 4.34 & 0.02 & 7236.75 \\
9 & 2.33 & 3.32 & 0.15 & 26.40 & 27.19 & 4.71 & 0.02 & 7238.9 \\
10 & 2.78 & 6.76 & 58.65 & 25.59 & 37.13 & 0.62 & 0.02 & 7246.8 \\
11 & 2.24 & 7.97 & 57.90 & 18.37 & 38.83 & 0.06 & 0.01 & 7264.09 \\
12 & 2.00 & 7.01 & 36.53 & 24.97 & 32.20 & 1.26 & 0.02 & 7237.47 \\
13 & 2.01 & 5.16 & 40.43 & 27.02 & 29.63 & 0.73 & 0.02 & 7270.96 \\
14 & 2.01 & 3.52 & 31.17 & 28.77 & 38.06 & 1.45 & 0.02 & 7365.9 \\
15 & 2.25 & 5.81 & 29.50 & 24.42 & 39.30 & 1.72 & 0.02 & 7281.44 \\
\hline
\end{tabular}
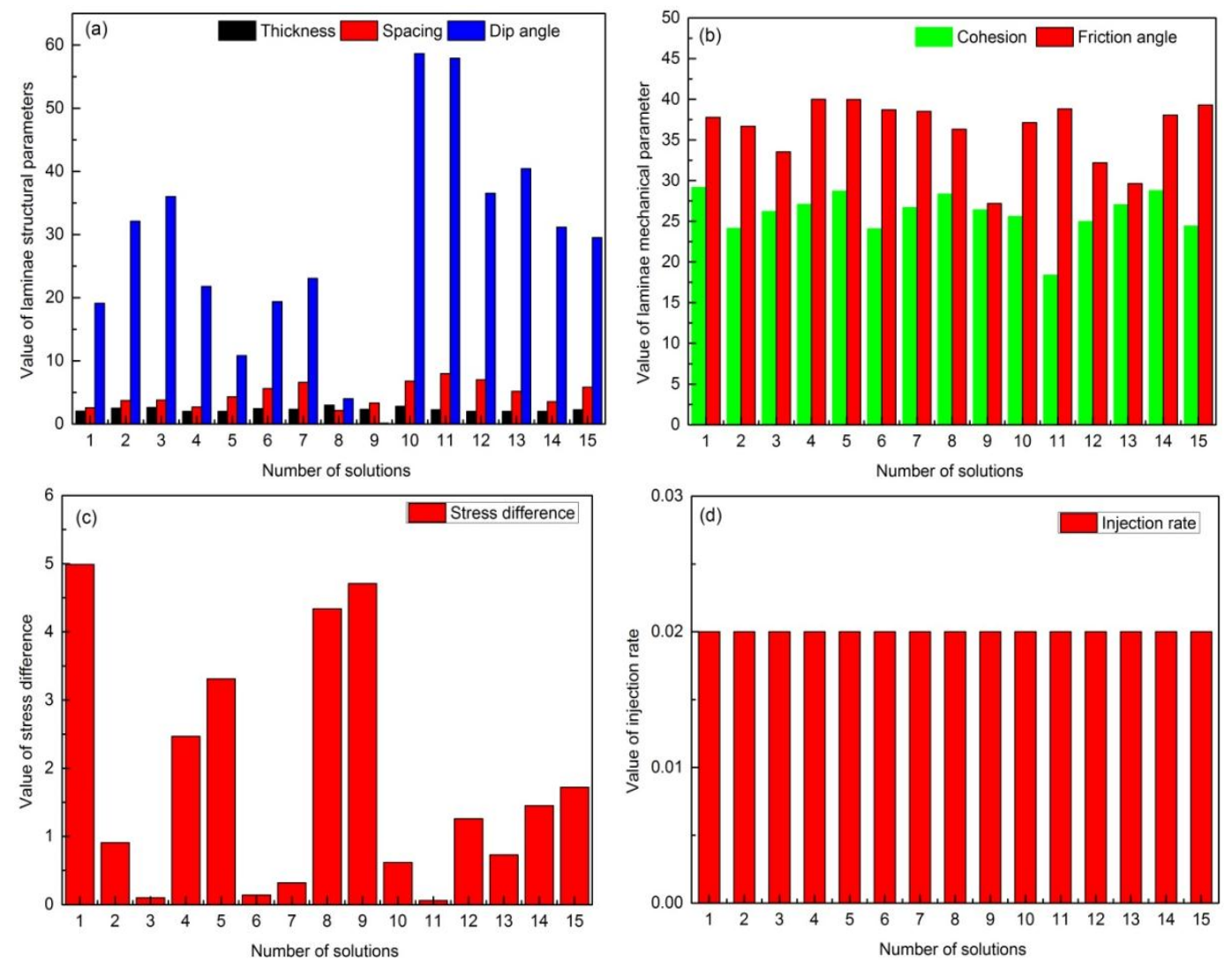

Fig.8 The effects of the studied factors to the desirable solutions of SRA. (a.Influence of the silty laminae structural parameter (i.e., thickness, spacing, and dip angle) on SRA desirable solutions; b. Influence of mechanical properties on SRA desirable solutions; $c$. Influence of stress difference on SRA; $d$. Influence of injection rate on SRA desirable solutions)

From Fig.8a, it can be seen that a medium thickness and spacing about $2 \mathrm{~mm}$ and $5 \mathrm{~mm}$, is beneficial to get the maximum SRA; when the dip angle is large, it is good to hydraulic fracturing effectiveness. From Fig.8b, the higher the mechanical properties, the smaller difference between silty laminae and shale layers properties is, which is desirable to maximize SRA. Mechanical properties control the damage and failure mechanism during hydraulic fracturing, according to Mohr-Coulomb shear failure criterion ((Jaeger and Cook, 1969), the fraction strength of the silty laminae affects the fracturing evolution to a large extent. From Fig.8c, it is not the case that the smaller the stress difference, the maximum stimulated area can reach for SRA, this result is consistent with the study of Guo er al. (2014). From Fig.8d, we can see that the injection rate is a critical factor controlling the stimulated area of SRA, the value of injection rate is set to maximum for all the desirable solutions. When SRA reaches the maximum, the injection rate is $0.02 \mathrm{~m}^{3} / \mathrm{d} / \mathrm{m}$. Fig.9a d shows the $3 D$ response surface for the optimal SRA with desirability value of 1.00 . The shape of response surface displays curved shape, which reflects 
the non-linear influential mechanism of the factors on SRA. The desirability value decreases with the increasing of laminae thickness. With the increase of laminae spacing, the value of desirability first increase and then decreases, at spacing of $5 \mathrm{~mm}$, it reaches the maximum. The desirability value increases with the increasing of dip angle, cohesion and friction angle. For factor of stress difference, the desirability value first decreases and then increases with the increase of its contrast. The factor of injection rate is a positive factor to enhance the desirability value of SRA.
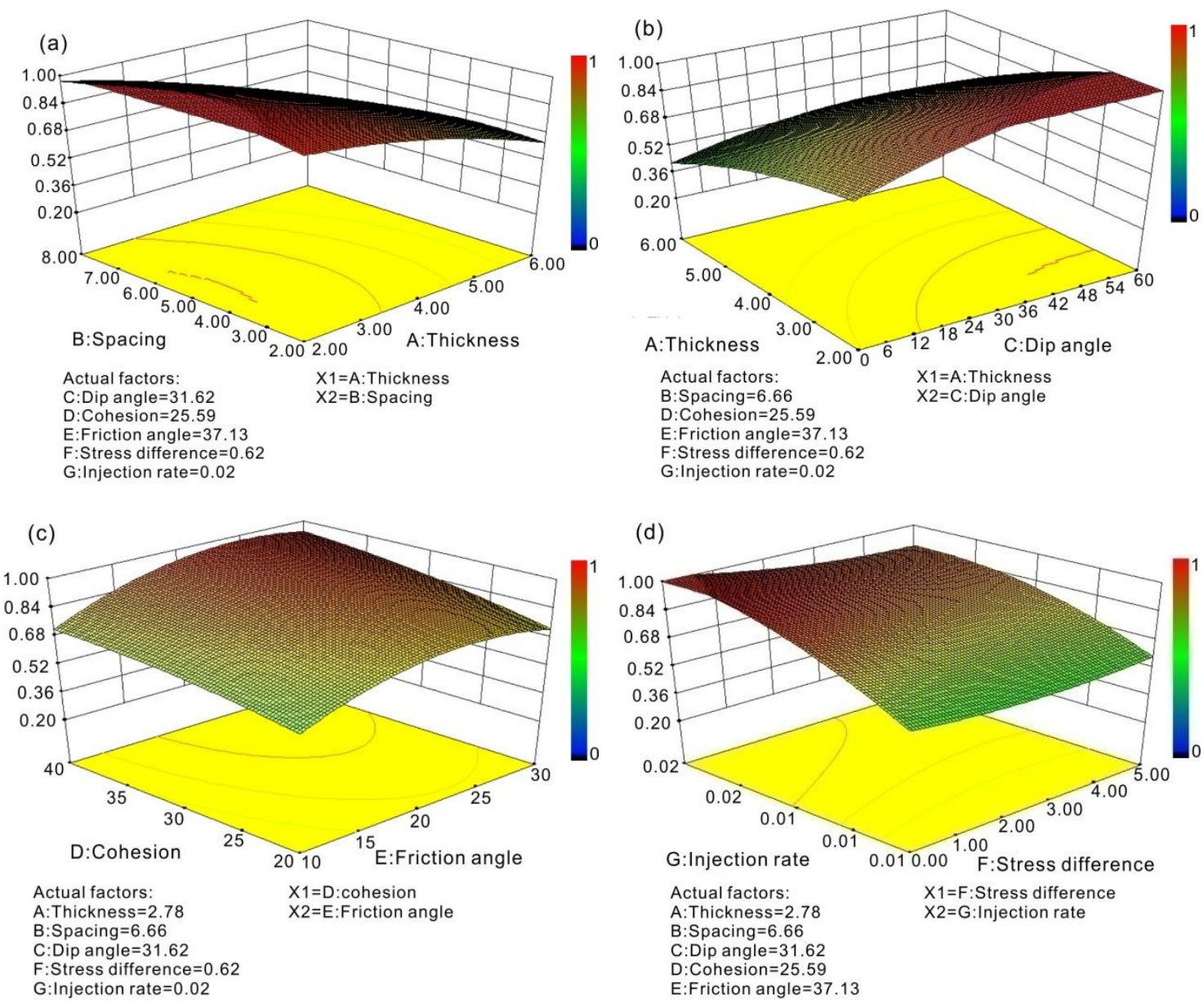

Fig.9 The 3D response surface for SRA with optimal project to reach desirability (a. influence of laminae spacing and thickness on model desirability; $b$. influence of laminae thickness and dip angle on model desirability; $c$. influence of laminae cohesion and friction angle on model desirability; $d$. influence of injection rate and stress difference on model desirability)

\section{Conclusions}

In the present paper, response surface methodology combined with a flow-stress-damage model are employed to explore the influence of the uncertain factors (i.e., laminae thickness, spacing, dip angle, cohesion, internal friction angle, in-situ stress difference, and injection rate) on fracturing network propagation. The proposed approach is practical and efficient for the design and optimization of hydraulic fracturing multi-parameter. SRA response surface model are reliable predicted values compared with the actual values of SRA.

From the RSM analysis of SRA, SRA is negative correlation to laminae thickness. Also, laminae spacing is negative factor to SRA. Due to the weak mechanical properties of silty laminae compared to shale matrix, silty laminae has a larger porosity than shale matrix, the injected fluid is mainly used to 
reactive the silty laminae, and leak-off in silty laminae is most serious; thus, generation of hydraulic fractures is unfavorable for cases with large thickness. With increase of spacing and stress difference, the communicate degree becomes weaker during hydraulic fracturing; this is unfavorable both for SRA. These two conclusions are consistent with the results of King (2010). Dip angle of silty laminae has a negative correlation with SRA. Generally speaking, the general opinion on the mechanism leading to the success of waterfrac in shale gas reservoirs is that a complex fracture network is created by the stimulation of pre-existing natural fractures; the silty laminae plays the role of natural fracture, which is actually a kind of cement-filled material. Fracture complexity is thought to be enhanced when pre-existing fractures are oriented at an angle to the maximum stress direction, or when both horizontal stresses and horizontal stress anisotropy are low, because these combinations of stress and natural fractures allow fractures in multiple orientations to be stimulated. The two mechanical parameters of cohesion and fraction angle, are both positive correlated with SRA. The reason for this result is that with lower mechanical strength, silty laminae are prone to damage and failure; once the laminae elements are damage, fluid leaks off into the silty laminae severely, the injected fluid is difficult used to generate hydraulic fractures, which reduces the interaction between hydraulic fractures and silty laminae. Injection rate is a positive factor to maximize the SRA, at a low injection rate, fluid tends to leak into the pre-existing discontinuities no matter how the fluid pressure is, and once the fluid leaks into the discontinuities, the pore pressure can rise far above the confining stress, and no induced hydraulic fracture can be generated.. At a large injection rate, the hydraulic fracture tends to cross the natural fracture due to the increase in the pressurization rate.

In summary, by RSM optimization, the optimal design solutions for silty laminae shale formations are obtained. The visualization of fracturing evolution in this numerical modeling throws new light on the understanding of interactions between silty laminae and hydraulic fractures. The analysis provides a deep insight into the sensitivity analysis as well as the contributions of different factors on maximizing the stimulated reservoir volume through a optimization model. It needs to be point that the properties of fluid such as viscosity and random natural fractures are not covered in this paper. These matters will be discussed in the further study.

\section{Acknowledgment}

The authors would like to thank the Editor and the anonymous Reviewers for their helpful and constructive comments. This work was supported by the National Natural Science Foundation of China (Grants Nos. 41502294, 41330643), Beijing National Science Foundation of China (Grants Nos. 8164070), China Postdoctoral Science Foundation Funded Project (Grants Nos. 2015M571118), and the Strategic Priority Research Program of the Chinese Academy of Sciences (Grants Nos. XDB10030000, XDB10030300, and XDB10050400).

\section{References}

Curtis, J.B., 2002. Fractured shale-gas systems. AAPG Bull. 86(11),1921-1938.

Montgomery, S.L., Jarvie, D.M., Bowker,K.A., Pollastro,R.M., 2005. Mississippian Barnett Shale, Fort Worth basin, north-central Texas: Gas-shale play with multi-trillion cubic foot potential. AAPG Bull. 89(2),155-175.

Jarvie, D.M., Hill,R.J., Ruble,T.E., Pollastro ,R.M., 2007.Unconventional shale-gas systems: the Mississippian Barnett Shale of north-central Texas as one model for thermogenic shale-gas assessment. AAPG Bull. 91(4),475-499.

King, G. E. 2010.Thirty years of gas shale fracturing: what have we learned? Paper SPE 133456 presented at the SPE Annual Technical Conference and Exhibition, Florence, Italy, 19-22 September.

Liu Q Y, Jin Z J, Wang Y, Han P L, Tao Y, Wang Q C, Ren Z L, Li W H. 2012. Gas filling pattern in Paleozoic marine carbonate reservoir of Ordos Basin. Acta Petrol Sin. 28, 847-858.

Tang, X, Zhang, J., Shan, Y., Xiong, J., 2012. Upper Paleozoic coal measures and unconventional natural gas systems of the Ordos Basin, China. Geosci. Front. 3, 863-873. 
Luo P, Ji L M. 2013. Reservoir characteristics and potential evalution of continental shale gas. Natural gas geosciences.24(5),1060-1068.

Tang, X., Zhang, J.C., Wang, X.Z., Yu, B.S., Ding, W.L., 2014. Shale characteristics in the southeastern Ordos Basin, China: Implications for hydrocarbon accumulation conditions and the potential of continental shales. International Journal of Coal Geology. 128-129,32-46.

Zhang, D .F., 2006. The research of sedimentary system of the Jurassic Yangchang formation in the south of the slope of Shanbei (in Chinese). Thesis dissertation for master degree, Northwest University.

Dong, G. L., 2012. The Evaluation of Chang7 Shale Gas Reservoir Characteristics of YanChang Formation in ZhenYuan and JingChuan Area. Chengdu University of Technology, Master Dissertation.

Lei, Y. H., Luo, X. R., Wang, X. Z., Zhang, L. X., Jiang, C. F., Yang, W., Yu, Y.X., Cheng, M., Zhang, L. K., 2015.Characteristics of silty laminae in Zhangjiatan Shale of southeastern Ordos Basin, China: Implications for shale gas formation. AAPG Bulletin. 99(4),661-687.

Boulis, A., Jayakumar,R., Rai,R., March,2013. Application of well spacing optimization work flow in various shale gas resources: lessons learned. In: Proceedings of IPTC2013:International Petroleum Technology Conference (PaperIPTC- 17150),26-28 March2013,Beijing,China.

Jahandideh A, Jafarpour B. Optimization of Hydraulic Fracturing Design Under Spatially Variable Shale Fracability[C]//SPE Western North American and Rocky Mountain Joint Meeting. Society of Petroleum Engineers, 2014.

Wang, Y., Li, X., Hu, R.L., Ma, C.F., Zhao, Z.Z., Zhang, B., 2016a. Numerical Evaluation and Optimization of Multiple Hydraulically Fractured Parameters Using a Flow-Stress-Damage Coupled Approach[J]. Energies, 2016, 9(5): 325.

Yu,W., Sepehrnoori,K., 2013. Optimization of multiple hydraulically fractured horizontal wells in unconventional gas reservoirs. In:Proceedings of SPE Production and Operations Symposium, 23-28 March 2013, Oklahoma City, Oklahoma.

Daniels, J., Waters,G., LeCalvez,J., Bentley,D., Lassek,J., 2007. Contacting more of the Barnett shale through an integration of real-time microseismic monitoring, petrophysics, and hydraulic fracture design. In: Proceedings of SPE Annual Technical Conference and Exhibition,12-140ctober 2007, Anaheim, California.

Ma, X., Plaksina,T.,Gildin,E., 2013. Optimization of placement of hydraulic fracture stages in horizontal wells drilled in shale gas reservoirs. In:Proceedings of Unconventional Resources Technology Conference. Society of Petroleum Engineers (Paper168780-MS),12-14 August 2013, Denver, Colorado.

Wilson, K., Durlofsky, L., 2012.Computational Optimization of Shale Resource Development Using Reduced-physics Surrogate Models. SPE Western Regional Meeting, 19-23 March 2012, Bakersfield, California.

Meyer, B.R., Bazan, L.W., Jacot, R.H., Lattibeaudiere, M.G., January, 2010. Optimization of multiple transverse hydraulic fractures in horizontal wellbores. In: Proceedings SPE Unconventional Gas Conference Society of Petroleum Engineers.

Ketter, A. A., Daniels, J. L., Heinze, J. R., \& Waters, G. 2006, January. A field study optimizing completion strategies for fracture initiation in Barnett shale horizontal wells. In SPE Annual Technical Conference and Exhibition. Society of Petroleum Engineers.

Fisher, M. K., Heinze, J. R., Harris, C. D., Davidson, B. M., Wright, C. A., \& Dunn, K. P., (2004, January). Optimizing horizontal completion techniques in the Barnett Shale using microseismic fracture mapping. In SPE Annual Technical Conference and Exhibition. Society of Petroleum Engineers.

Fisher, M. K., Wright, C. A., Davidson, B. M., Goodwin, A. K., Fielder, E. O., Buckler, W. S., \& Steinsberger, N. P., 2002, January. Integrating fracture mapping technologies to optimize stimulations in the Barnett Shale. In SPE Annual Technical Conference and Exhibition. Society of Petroleum Engineers.

Rickman, R., Mullen, M. J., Petre, J. E., Grieser, W. V., \& Kundert, D., 2008, January. A practical use of shale petrophysics for stimulation design optimization: All shale plays are not clones of the Barnett Shale. In SPE Annual Technical Conference and Exhibition. Society of Petroleum Engineers. 
Wang, Y., Li, X., Zhao, Z. H., Zhou, R.Q., Zhang, B., 2016b. Contributions of non-tectonic micro-fractures to hydraulic fracturing-A numerical investigation based on FSD model. Science China Earth Sciences. 59(4), 1-15.

Wang, Y., Li, X., Zhou, R. Q., Zheng, B., Zhang, B., Wu, Y.F., 2015. Numerical evaluation of the effect of fracture network connectivity in naturally fractured shale based on FSD model. Science China: Earth Sciences, 58: 1-14, doi: 10.1007/s11430-015-5164-9

Warpinski N R, Tuefel L W. 1987., Influences of Geologic Discontinuities on Hydraulic Fracture Propagation.SPE J.P.T,February, pp 209-220.

Tang, C .A., Tham, L. G., Lee, P. K. K., 2002. Coupled analysis of flow, stress and damage (FSD) in rock failure. Int J Rock Mech Min Sci, 39,477-489.

Myers, R. H., Montgomery, D. C., 2002. Response Surface Methodology:Process and Product Optimization Using Designed Experiments, John Wiley and Sons,Hoboken, NJ, USA.

Kiefer,J., Wolfowitz, J., 1959.Optimum designs in regression problems. The Annals of Mathematical Statistics.30(2), 271-294.

Nagel, N., Gil, I., Sanchez-Nagel, M., Damjanac, B., 2011. Simulating Hydraulic Fracturing in Real Fractured Rock -Overcoming the Limits of Pseudo 3D Models. SPE 140480, presented at the SPE HFTC in Woodlands, Texas, USA, 24-26 January.

Guo, T., Zhang, S., Qu, Z., Zhou, T., Xiao, Y., Gao, J., 2014. Experimental study of hydraulic fracturing for shale by stimulated reservoir volume. Fuel.128, 373-380.

Jaeger, J. C., Cook, N. G., 1979. Fundamentals of rock mechanics, 3rd edn. Chapman \& Hall, London 